\title{
Quantitative genetics of ultrasonic advertisement signalling in the lesser waxmoth Achroia grisella (Lepidoptera: Pyralidae)
}

\author{
ROBERT D. COLLINS*, YIKWEON JANG, KLAUS REINHOLD† \\ \& MICHAEL D. GREENFIELD \\ Department of Entomology, University of Kansas, Lawrence, KA 66045, U.S.A.
}

\begin{abstract}
Males of the lesser waxmoth Achroia grisella (Lepidoptera: Pyralidae) produce ultrasonic advertisement signals attractive to females within several metres. Previous studies showed that females prefer male signals that are louder, delivered at a faster rate, and have a greater asynchrony between pulses produced by the right and left wings. These three signal characters vary considerably within populations but are repeatable within individuals. Breeding experiments employing half-sib designs were conducted on both collectively and individually reared moths to determine genetic variance within and covariance among these signal characters. Heritabilities of all signal characters were significant among collectively reared moths. Heritabilities for signal rate and right-left wing asynchrony interval were not significant, however, among individually reared moths, suggesting the presence of significant nonadditive genetic variance or common environmental variation. Development time was also significantly heritable, but only under individual rearing. The only significant genetic correlation was between signal rate and length of the right-left wing asynchrony and this was negative. Our findings on heritability of signal characters are consistent with a coevolutionary sexual selection mechanism, but the absence of signal $\times$ development genetic correlation fails to support specifically a good-genes mechanism. The variation in heritability among conditions suggests that environmental variance may be high, and may render selection on signal characters by female choice ineffective. Thus, additive genetic variance for these characters may be maintained in the presence of directional female choice.
\end{abstract}

Keywords: additive genetic variance, female choice, genetic correlation, good genes model, heritability, sexual selection.

\section{Introduction}

According to sexual selection theory (Andersson, 1994), many behavioural and morphological traits specifically associated with mating evolved as a result of intra- and intersexual selection. In the latter process one sex, generally the female, mates preferentially with certain members of the other sex. Such preferences may be based on material benefits that a female directly obtains by mating with certain males: resources defended on a territory or transferred at mating, parental care, avoidance of parasite infection and ease of localization.

*Correspondence. E-mail: rcollins@falcon.cc.ukans.edu

$\uparrow$ Present address: Institut für Evolutionsbiologie und Ökologie der Universität Bonn, An der Immenburg 1, D-53121 Bonn, Germany.
Nonetheless, in many animal species females discriminate among potential mates even when they do not receive any apparent material benefit directly influencing their survival or fecundity. In such cases, the origin and maintenance of female mate preference remain a major problem in evolutionary biology.

Where no apparent direct, material benefits are conferred at mating, it is proposed that discriminating females receive indirect, 'genetic' benefits from the chosen male's gametes. In the 'arbitrary' (or 'Fisherian') model of indirect sexual selection, the genetic benefits are 'attractiveness genes' that are expressed in the next generation. By choosing attractive males, a female is likely to produce sons that display their father's aesthetically appealing features and later succeed in the 'sexual selection arena' (Lande, 1981). Alternatively, 
in 'good-genes' (or 'viability indicator') models the genetic benefits also include 'viability genes' that enhance offspring survival and growth (Pomiankowski, 1988). Here, females who mate with attractive males produce offspring that not only display their father's attractive features (if they are sons) but have superior survivorship and maturation characteristics as well.

Both the arbitrary and good-genes models are coevolutionary in that the male character and the female preference coevolve in a reciprocally reinforcing manner (Houde, 1997). Coevolutionary models of indirect sexual selection assume three fundamental genetic conditions: significant additive genetic variance (heritability) in the male character, heritable female preference traits, and genetic covariance between male and female traits generated by female preference for particular male phenotypes. Such covariance reinforces the sexual selection process and may lead to exaggeration of both the male character and the female preference. Various recent studies employing quantitative genetic approaches have confirmed heritability for male characters (e.g. see references in Andersson, 1994). Nonetheless, the factors that maintain additive genetic variance in natural populations remain largely unknown. This problem, often termed 'the paradox of the lek' (Ritchie, 1996), is receiving renewed theoretical treatment by various workers (e.g. Pomiankowski \& Møller, 1995; Rowe \& Houle, 1996).

Here, we report a quantitative genetic study of male signal characters in the lesser waxmoth Achroia grisella (Lepidoptera: Pyralidae). We conducted two parallel breeding experiments and calculated the heritability of and correlations among those signal characters subject to directional sexual selection by female choice. Because previous work has suggested that a good-genes mechanism of sexual selection may operate in $A$. grisella under certain environmental conditions (Jia \& Greenfield, 1997), we also determined the correlations between signal characters and development time. Heritabilities were measured under two different environmental conditions, and variation in these values between conditions suggests ways in which the observed additive genetic variance is maintained.

\section{Natural history and acoustic signalling in Achroia grisella}

Achroia grisella is a cosmopolitan symbiont of honeybee (Apis mellifera) colonies where the larvae feed mostly on residual stored food and organic detritus. Adults, having atrophied proboscises, neither feed nor drink but remain in the vicinity of the honeybee colony during their brief (7-14 days) life spans. Both males and females exit the hive immediately after eclosion, which normally occurs close to dusk, expand their wings, and commence sexual activities shortly thereafter on or near the hive (Greenfield \& Coffelt, 1983).

Unlike most moths, in which pair formation is typified by female olfactory signalling and male searching, A. grisella males produce ultrasonic advertisement signals that attract receptive females within a radius of several metres (Spangler et al., 1984). Both males and females hear sounds extending over a frequency range from 30 to $120 \mathrm{kHz}$ with a pair of abdominal tympanal organs. Females usually run on the substrate, rather than fly, during phonotaxis towards a signalling male. The males remain perched and stationary while signalling and do not move towards females until the pair contact. An individual male may continue acoustic signalling without interruption for $6-10 \mathrm{~h}$ each night. Males also emit an odour (a combination of two aldehydes) from forewing glands, but its function is unclear. Experiments using simulated signals show that the ultrasonic signal alone is as attractive as a live male, i.e. the acoustic signal is both necessary and sufficient for pair formation (Spangler et al., 1984).

Achroia grisella males produce ultrasonic signals by wing fanning, which causes a pair of tymbals on the tegulae (axillary sclerites on the thorax) to buckle in and out. Females, who are silent, lack such tymbals. Males remain perched and stationary while wing fanning and produce $\approx 50$ wingstrokes $\mathrm{s}^{-1}$ at $25^{\circ} \mathrm{C}$. A male's tymbals buckle twice during each wingstroke (complete cycle of wing movement), once on the upstroke and once on the downstroke. Each tymbal buckling results in emission of a highly damped $100-\mu \mathrm{s}$ pulse of sound. Owing to slightly asynchronous wing movement, a male's two tymbals produce a pair of pulses during each upstroke and downstroke that are usually separated by a brief $(100-400 \mu \mathrm{s})$ gap. The sound pulses are loud (amplitude $\approx 95 \mathrm{~dB}$ sound pressure level at $1 \mathrm{~cm} ; 0 \mathrm{~dB}$ re $20 \mu \mathrm{Pa}$ ), broadcast rather omnidirectionally, and include frequencies from 70 to $130 \mathrm{kHz}$ (peak frequency $\approx 100 \mathrm{kHz}$ ) (Spangler et al., 1984; Snedden et al., 1994). Females prefer male signals that are louder (measured as peak pulse amplitude), delivered at a faster rate (greater wingstroke frequency), and include longer asynchrony intervals (the temporal gap between pulses produced by right and left tymbals) (Jang \& Greenfield, 1996, 1998; Jang, 1997). These three signal characters vary greatly between males but are highly repeatable within individuals ( $r \geq 0.66$; Jang et al., 1997).

Respirometric studies have shown that a relatively high expenditure of metabolic energy is necessary, but not sufficient, to produce attractive signals in A. grisella (Reinhold et al., 1998). This requirement reflects the positive relationship between pulse rate and energy expenditure. Under certain favourable diet and 
temperature conditions the male offspring of attractive males develop faster than the offspring of unattractive males (Jia \& Greenfield, 1997). However, this relationship is context dependent, being absent under other environmental conditions.

Females normally mate only once and are then unreceptive (Greenfield \& Coffelt, 1983). Males can mate approximately once every $24 \mathrm{~h}$, and female fecundity is unaffected by male mating history. Thus, it is unlikely that material benefits in the form of critical spermatophore materials, which represent less than $1 \%$ of the male's body mass, are transferred to the female at mating. Because paternal care and other material benefits appear to be inconsequential, female choice for male signals in A. grisella may be based primarily on genetic benefits and maintained by an indirect sexual selection mechanism.

\section{Materials and methods}

\section{Population studied and general conditions}

A laboratory population of A. grisella was founded from several hundred adults collected at honeybee colonies near Auburn, AL. We employed a breeding protocol that maximized effective population size in this stock population. Larvae were reared on a standardized diet of cereals, Brewer's yeast, glycerol, honey, beeswax and water. Temperature $\left(\approx 25.5^{\circ} \mathrm{C}\right)$, photoperiod (12:12 L:D), and density ( $\approx 1$ larva per $1 \mathrm{~g}$ diet) were maintained such that generations were approximately 45 days long. The experiments reported below were conducted on insects from the 16th to the 18th generation. To insure that all adults were unmated prior to testing, we placed late-instar larvae individually in 30$\mathrm{mL}$ clear plastic containers with $\approx 1 \mathrm{~g}$ of diet to complete their development.

We recorded male signals in one of two similarly constructed semianechoic rooms $(3 \times 3.5 \times 2.5 \mathrm{~m})$ illuminated by $25-\mathrm{W}$ red incandescent bulbs $(<1$ lux $)$. Tests were conducted at $25-26^{\circ} \mathrm{C}$ during the first $4 \mathrm{~h}$ of the scotophase, the period of peak signalling and sexual activity (Greenfield \& Coffelt, 1983; Jang et al., 1997).

\section{Experimental design}

Quantitative genetic parameters for signalling and development were measured for insects taken from the stock population described above. Heritabilities and genetic correlations were estimated using half-sib analysis (Falconer, 1981). Both of the experiments described below were conducted during the same 4-month period (October 1996-January 1997).
Experiment 1: Collective rearing A North Carolina Experiment I design (NCI) (Kearsey \& Pooni, 1996) was used to estimate genetic variance in signal characters and development time. Virgin males and females were collected randomly from the stock population and mated when they were 1-3 days old. Each male was paired with a different female on three consecutive days. Approximately 40 eggs from each pairing were chosen randomly and placed on 25-30 g of diet in a clear plastic box $(16 \times 12 \times 6.5 \mathrm{~cm}$ deep $)$. If one or more of the three females mated to a given male failed to produce eggs, none of the offspring of that male was tested.

The offspring of each male-female pair were reared collectively until they were pupae or last-instar larvae (approximately 35 days after oviposition). Pupae (or larvae) were then placed individually in $30-\mathrm{mL}$ clear plastic cups with $\approx 1 \mathrm{~g}$ diet. These cups were checked daily until adult eclosion. Development times (oviposition to adult eclosion) for all male and female offspring were recorded for 47 sires paired with 3 dams each. Mean (SD) offspring per sire and per dam were 32.8 (7.0) and 10.9 (3.4), respectively.

The ultrasonic signals of all male offspring were recorded on the 1 st or 2 nd day post emergence when they were $24-48$ or $48-72 \mathrm{~h}$ old. Although male-emitted signal characters change with age, these changes occur primarily when males are 3 or more days old; signal characters of 1- and 2-day-old males do not differ significantly (Snedden et al., 1994;).

Experiment 2: Individual rearing Males were paired with females as above, but offspring were transferred as 2 nd instar larvae to individual $30-\mathrm{mL}$ plastic cups with $1 \mathrm{~g}$ of diet. Thus, most larval development occurred in the absence of competition. We noted the development times of all eclosing offspring and recorded the ultrasonic signals of every third eclosing male. Thirty-three males were paired with an average of 1.9 females, and the mean (SD) number of offspring per mating was 7.1 (1.2). The basic NCI design was also used in this experiment, but the offspring of males that mated with fewer than three females were reared and included in the analysis.

In both experiments larvae were reared at the same mean temperature $\left(\approx 25 \cdot 5^{\circ} \mathrm{C}\right)$. However, the daily temperature range in expt $1\left(24-27^{\circ} \mathrm{C}\right)$ exceeded that in expt $2\left(25-26^{\circ} \mathrm{C}\right)$. All signal recordings in a given experiment were made in the same semianechoic room. Temperatures were $\approx 25.5^{\circ} \mathrm{C}$ (range $25-26^{\circ} \mathrm{C}$ ) at the time of recording in both experiments.

\section{Signal recording and analysis}

We recorded ultrasonic signals of males held individually in cylindrical screen cages $(2.5 \times 2.5 \mathrm{~cm}$ diameter $)$. 
The cage screen had no effect on transmission of the ultrasonic signals (Jang et al., 1997). Cages were separated by at least $25 \mathrm{~cm}$ to minimize any potential influence of neighbours on a male's signalling.

We recorded each male with a 0.64- $\mathrm{cm}$ condenser microphone (ACO Pacifica, model 7016; frequency response $\pm 6 \mathrm{~dB}$ from 10 to $160 \mathrm{~Hz}$ ) fitted with a preamplifier (ACO model 4012). The microphone was positioned outside the male's cage and orientated towards its dorsum at a standard distance. Output from the microphone-preamplifier unit was amplified with an ACO Pacifica model PS9200 amplifier and sent to the input port of a sound card installed in a personal computer (80486 processor; $66 \mathrm{MHz}$ clock speed). The sound card (SuperSound Engineering Version, SiliconSoft, San Jose, CA) included 8-bit analogue-digital and digital-analogue converters, each with a maximum sampling rate of $1 \mathrm{MHz}$. In operation, signals were sampled at 297 or $398 \mathrm{kHz}$ and saved to a computer file using custom software developed for ultrasound recording.

We recorded the signal of each male for $0.164 \mathrm{~s}(7-10$ complete cycles of wing movement). Three consecutive cycles were analysed. Peak amplitude was calculated as the average maximum amplitude (measured on a linear scale) of all pulses in the three cycles. Signal rate was computed as the reciprocal of mean cycle duration. Asynchrony interval was measured as the average delay between pulses produced by the right and left wings during the up and down wing strokes.

\section{Genetic parameter estimation}

Genetic parameters were estimated separately for each experiment. Heritability estimates were computed using nested analysis of variance (Model II) for unequal sample sizes to allocate observed variation among sire and dam components (Sokal \& Rohlf, 1981, pp. 294299). Mean squares for the sire and dam components were pooled when the dam component was not significant (Sokal \& Rohlf, 1981; pp. 285-286). Heritability estimates were then made using the method described by Becker (1975, pp. 50-52). Variances of the variance components were estimated with the procedures of Searle (1971, pp. 447-448) and used to estimate standard errors for the heritabilities (Becker, 1975; p. 45).

We also calculated the coefficients of additive genetic variance for signal characters and development time. These values provide additional information about the ability of a population to respond to selection (Houle, 1992).

Phenotypic, genetic and environmental correlations were estimated for each experiment using methods described by Becker (1975; pp. 105-110). Standard errors for genetic correlations were estimated using a jackknife method. Separate estimates were made by omitting the offspring of one male and calculating genetic correlations based on the offspring of the remaining males. Estimates were made for all possible subsets thus constructed. Variation in this set was then used to calculate variance in the genetic correlation for the entire data set. Standard errors for phenotypic and environmental correlations were estimated using the methods outlined by Becker (1975; pp. 105-110).

Genetic correlations are reported for all pairs of characters regardless of their heritabilities. However, genetic correlations between traits that are not significantly heritable are difficult to interpret and could reflect Type I errors (rejection of a true null hypothesis) or nonadditive genetic variance.

Distributions for each variable within each experiment were compared to the normal distribution using the Kolmogorov-Smirnov test (Sokal \& Rohlf, 1981; p. 440). Where necessary and possible, data were transformed to approximate normality. Transformations used for particular variables are listed in Tables $1-3$.

Analysis of variance was used to assess the significance of differences in mean signal characters between the two experiments. Homogeneity of variance was tested using the Levene test (Norusis, 1990). Transformed data were used when appropriate for all comparisons.

\section{Results}

\section{Signal characters and development}

Although the insects used in the two experiments were derived from the same stock population at approximately the same time, we observed significant differences in signal character means and variances (Table 1). Males reared collectively produced signals with lower peak amplitudes and longer asynchrony intervals than those reared individually. Collectively reared males also developed more slowly. Because available food was more than adequate for the number of larvae reared, the observed difference in development may have resulted from extended larval interactions under collective rearing. This result is consistent with that reported by Jia \& Greenfield (1997).

Signal characters and development times were more variable among males reared individually. Variances for peak amplitude, signal rate and development time in the two experiments were not homogeneous (Levene test; $P<0.001)$. Possibly, the reduced variance among males reared collectively resulted from the common environments established by this rearing condition. 
Table 1 Phenotypic means $\uparrow( \pm \mathrm{SE})$ of ultrasonic signal characters and development time for male offspring of Achroia grisella reared collectively (expt 1) and individually (expt 2) using NCI half-sib designs

\begin{tabular}{lcc}
\hline & \multicolumn{2}{c}{ Rearing condition } \\
\cline { 2 - 3 } Character & Collective & Individual§ \\
\hline Peak amplitude & $22.08(0.16) \mathrm{b}$ & $28.04(0.34) \mathrm{a}$ \\
Signal rate $\left(\mathrm{s}^{-1}\right)$ & $46.94(0.11) \mathrm{a}$ & $46.77(0.15) \mathrm{a}$ \\
$\begin{array}{l}\text { Asynchrony } \\
\quad \text { interval }(\mu \mathrm{s})\end{array}$ & $575.20(9.59) \mathrm{a}$ & $520.06(17.73) \mathrm{b}$ \\
$\begin{array}{l}\text { Development } \\
\text { time (days) }\end{array}$ & $44.46(0.06) \mathrm{a}$ & $42.09(0.11) \mathrm{b}$ \\
\hline
\end{tabular}

$\dagger$ Means within rows not followed by the same letter are significantly different; one-way ANOvA, $P<0.05$; peak amplitude, ordered on a linear scale, transformed by $X=\ln (X)$; asynchrony interval transformed by $X=X^{1 / 2}$.

†Collective rearing: $n=1540$ offspring from 47 males mated to three females each.

§Individual rearing: offspring from 33 males mated to an average of 1.88 females each; for signal characters, $n=443$; for development time, $n=1067$.

\section{Heritability of signal characters}

All of the measured signal characters were significantly heritable for males reared collectively $(P<0.05$; Table 2). Heritabilities for peak amplitude and signal rate both exceeded 0.40. Although heritability for asynchrony interval was only 0.08 , it was statistically significant.

Among males reared individually, heritability based on the sire variance component (paternal heritability, $h_{\mathrm{s}}^{2}$ ) was significant for peak amplitude only $\left(h_{\mathrm{s}}^{2}=0.69\right)$. For signal rate, $h_{\mathrm{s}}^{2}$ was low and nonsignificant, but heritability based on the dam component (maternal heritability) was both high (0.45) and significant. This discrepancy suggests a significant nonadditive genetic component or common environmental variation resulting from the collective rearing of each full-sib family (see Falconer, 1981). Heritability for asynchrony interval was low and nonsignificant, although marginally so $(P=0.07)$.

Estimated coefficients of additive genetic variation $\left(\mathrm{CV}_{\mathrm{A}}\right)$ for peak amplitude were high $(>19 \%)$ and consistent with estimated heritabilities for this character (Table 2). This indicates the potential for significant response to selection by female preferences for louder signals.

Although the heritability $\left(h_{\mathrm{s}}^{2}\right)$ of signal rate was 0.40 for males reared collectively, $\mathrm{CV}_{\mathrm{A}}$ estimates were low $(<6.2)$ in both rearing conditions. Mean signal rate did not differ among environments, but total phenotypic variance was greater for males reared individually. Therefore, additive genetic variance was comparable in the two environments, but environmental variance was greater for males reared individually.

Heritability for asynchrony interval was low and not statistically significant. However, $\mathrm{CV}_{\mathrm{A}}$ estimates were

Table 2 Heritabilities $\left(h^{2} \pm \mathrm{SE}\right)$ and coefficients of additive genetic variation $\left(\mathrm{CV}_{\mathrm{A}}\right)$ of ultrasonic signal characters and development time for male offspring of Achroia grisella reared collectively (expt 1) and individually (expt 2) using NCI half-sib designs

\begin{tabular}{|c|c|c|c|c|c|}
\hline \multirow[b]{3}{*}{ Character } & \multirow[b]{3}{*}{ Variance source } & \multicolumn{4}{|c|}{ Rearing condition } \\
\hline & & \multicolumn{2}{|c|}{ Collective§ } & \multicolumn{2}{|c|}{ Individual } \\
\hline & & $h^{2}$ & $\mathrm{CV}_{\mathrm{A}}$ & $h^{2}$ & $\mathrm{CV}_{\mathrm{A}}$ \\
\hline \multirow[t]{2}{*}{ Peak amplitude $\dagger$} & Sire & $0.45(0.15)^{* *}$ & 19.08 & $0.69(0.21)^{* *}$ & 21.20 \\
\hline & Dam & $0.56(0.13)^{* *}$ & 21.28 & NS & NS \\
\hline \multirow[t]{2}{*}{ Signal rate } & Sire & $0.40(0.13)^{* *}$ & 5.82 & $0.07(0.19)$ & 1.79 \\
\hline & Dam & $0.46(0.10)^{* *}$ & 6.24 & $0.45(0.23)^{*}$ & 4.53 \\
\hline \multirow[t]{2}{*}{ Asynchrony interval\$ } & Sire & $0.08(0.05)^{*}$ & 18.51 & $0.22(0.15)$ & 33.66 \\
\hline & Dam & NS & NS & NS & NS \\
\hline \multirow[t]{2}{*}{ Development time } & Sire & $0.10(0.14)$ & 1.67 & $0.66(0.36)^{*}$ & 6.94 \\
\hline & Dam & $1.12(0.16)^{* *}$ & 5.60 & $1.21(0.28)^{* *}$ & 9.39 \\
\hline
\end{tabular}

NS dam component not significant, ANOvA, $P>0.05$.

* Sire or dam component significant, ANOVA, $P<0.05$; ** $P<0.01$.

$\dagger$ Peak amplitude, ordered on a linear scale, transformed by $X=\ln (X)$.

†Asynchrony interval transformed by $X=X^{1 / 2}$.

§Collective rearing: $n=1540$ offspring from 47 males mated to three females each.

TIndividual rearing: offspring from 33 males mated to an average of 1.879 females each; for signal characters, $n=443$; for development time, $n=1067$. 
18.5 and 33.7 for males reared collectively and individually, respectively. Therefore, female preference for longer asynchrony intervals could yield a significant selection response even though heritability estimates were low.

\section{Heritability of development time}

Heritability of development time was significant $\left(h_{\mathrm{s}}^{2}=0.66 \pm 0.36\right)$ only among males reared individually (Table 2). A previous study using the same stock population, however, found significant heritability of development time among males reared either individually $\left(h_{\mathrm{s}}^{2}=0.43 \pm 0.20\right)$ or collectively $\left(h_{\mathrm{s}}^{2}=0.60 \pm 0.22\right)$ (Jia \& Greenfield, 1997). Causes for the low heritability among males reared collectively are unknown. Taken together, these data suggest that variance in development time may contain a significant genetic component. However, relatively low $\mathrm{CV}_{\mathrm{A}}$ estimates (Table 2) indicate that observed heritabilities may overstate the responsiveness of development time to selection.

Estimated paternal and maternal heritabilities of development time differed greatly (Table 2). Again, this discrepancy suggests the presence of nonadditive genetic variance or common environmental variation.

\section{Correlations}

Phenotypic, genetic, and environmental correlations were estimated for all pairs of signal characters and development time (Table 3). Correlations between signal characters were generally low and nonsignificant, except between signal rate and asynchrony interval. The significant positive phenotypic correlation between peak amplitude and signal rate reported by (Jang et al., 1997) for another A. grisella population was not found in the current study.

Phenotypic and environmental correlations between signal rate and asynchrony interval were negative for males in both experiments. This relationship is consistent with that reported by Jang et al. (1997) and may result from physiological constraints. The asynchrony interval reflects a delay between movement of the right and left wings on the up- or down-strokes, and it may become difficult to maintain lengthy delays as wing beat frequency increases.

Large differences between the genetic and environmental correlations between signal rate and asynchrony interval were observed. These differences suggest that the effects of genetic and environmental variation may affect these signal characters via different mechanisms (Falconer, 1981). The identity of these mechanisms remains unknown.

The only significant genetic correlation was found between signal rate and asynchrony interval among males reared collectively. This genetic correlation could reflect a physiological linkage between the signal characters, suggesting that signal rate and asynchrony interval may not be independent characters in either a behavioural or a statistical sense.

Low but significant negative phenotypic and environmental correlations between development time and both peak amplitude and signal rate were found for males reared collectively. Males that take longer to develop tended to produce louder signals delivered at faster signal rates, features that are more attractive to females

Table 3 Phenotypic (P), genetic (G), and environmental (E) correlations $(r \pm$ SE) among ultrasonic signal characters $(\mathrm{PA}=$ peak amplitude $\dagger, \mathrm{SR}=$ signal rate, $\mathrm{AI}=$ asynchrony interval $)$ and development time (DT) for male offspring of Achroia grisella reared collectively (expt 1) and individually (expt 2) using NCI half-sib designs

\begin{tabular}{|c|c|c|c|c|c|c|}
\hline \multirow[b]{3}{*}{ Correlation } & \multicolumn{6}{|c|}{ Rearing condition } \\
\hline & \multicolumn{3}{|c|}{ Collective§ } & \multicolumn{3}{|c|}{ Individual } \\
\hline & $P$ & $\mathrm{G}$ & $\mathrm{E}$ & $\mathrm{P}$ & $\mathrm{G}$ & $\mathrm{E}$ \\
\hline $\mathrm{PA} \times \mathrm{SR}$ & $0.05(0.04)$ & $0.30(0.35)$ & $-0.09(0.08)$ & $-0.08(0.05)$ & $-1.05(3.27)$ & $0.16(0.13)$ \\
\hline $\mathrm{PA} \times \mathrm{AI}$ & $0.00(0.02)$ & $0.03(0.29)$ & $0.05(0.34)$ & $0.09(0.05)^{*}$ & $0.29(0.24)$ & $0.02(0.01)$ \\
\hline $\mathrm{SR} \times \mathrm{AI}$ & $-0.11(0.03)^{* *}$ & $-0.43(0.25)^{*}$ & $-0.10(0.03)^{* *}$ & $-0.24(0.05)^{* *}$ & $0.33(1.27)$ & $-0.24(0.06)^{* *}$ \\
\hline $\mathrm{DT} \times \mathrm{PA}$ & $-0.08(0.04)^{*}$ & $-0.02(0.67)$ & $0.24(0.12)^{*}$ & $-0.02(0.06)$ & $0.20(0.39)$ & $-0.28(0.78)$ \\
\hline $\mathrm{DT} \times \mathrm{SR}$ & $-0.16(0.03)^{* *}$ & $-0.11(0.62)$ & $-0.14(0.03)^{* *}$ & $-0.05(0.05)$ & $0.99(3.99)$ & $-0.28(0.33)$ \\
\hline $\mathrm{DT} \times \mathrm{AI}$ & $0.01(0.03)$ & $0.35(0.68)$ & $-0.02(0.06)$ & $0.00(0.06)$ & $-0.11(0.32)$ & $-0.03(4.01)$ \\
\hline
\end{tabular}

$* P<0.05 ; * * P<0.01$.

$\dagger$ Peak amplitude, ordered on a linear scale, transformed by $X=\ln (X)$.

$\$$ Asynchrony interval transformed by $X=X^{1 / 2}$.

$\S$ Collective rearing: $n=1540$ offspring from 47 males mated to three females each.

-Individual rearing: $n=443$ offspring from 33 males mated to an average of 1.879 females each.

(c) The Genetical Society of Great Britain, Heredity, 83, 644-651. 
(Jang \& Greenfield, 1996). Development time is also correlated with adult weight $(r=0.52 ; \quad P<0.001$; K. Reinhold, unpublished data). Thus, males that take longer to develop are larger and produce more attractive signals.

\section{Discussion}

Our finding that the heritabilities of two characters, peak amplitude and signal rate, of ultrasonic advertisement signalling in male $A$. grisella are high (Table 2) is consistent with earlier work showing that these signal characters are highly repeatable (Jang et al., 1997). These previous measurements, however, showed that the asynchrony interval, also critical to a male's attractiveness, is highly repeatable $(r=0.84)$. The low heritability of asynchrony interval may reflect a large environmental variance component. Similarly, the markedly different heritabilities of signal rate for males reared collectively and individually $\left(h_{\mathrm{s}}^{2}=0.40\right.$ and 0.07 , respectively) suggest that environmental variance may also be significant for this character.

Environmental variation is assumed to be largely attributable to differences in the extent of larval interactions in the collective and individual rearing conditions. However, the small difference in rearing temperature range between the two experiments may also have contributed to environmental variation.

The significant heritabilities found for peak amplitude and signal rate in A. grisella parallel findings for male signal characters in several other acoustic insects (e.g. Charalambous et al., 1994; Hedrick, 1994; but see Webb \& Roff, 1992 for nonsignificant values). Because a significant additive genetic component of variance for the male trait(s) is prerequisite for indirect mechanisms of sexual selection, these findings suggest that either arbitrary or good-genes selection could be responsible for at least part of the observed patterns of female choice in these species. Operation of indirect sexual selection mechanisms also requires significant additive genetic variance for female preference and a genetic correlation between the male trait and female preference. In A. grisella, evidence for heritable variation in female preference has recently been found (Jang, 1997), but examination of associations between male signal characters and female preferences has thus far failed to reveal any positive evidence for genetic correlation (Jang, 1997). The absence of genetic correlation may represent a laboratory artifact, though, as the breeding protocol used in the experimental populations could have reduced linkage disequilibrium and therefore the likelihood of such correlation (see Bakker \& Pomiankowski, 1995).

In light of the problems attending measurement of male signal $\times$ female preference correlation in the laboratory, can our determinations of the heritability of signal characters be considered as measures applicable to natural A. grisella populations? Traditionally, lower environmental variance is expected in laboratory than in natural populations; indeed, most laboratory studies attempt to minimize such variance. Because of greater phenotypic variability or genotype-environment interactions in the field, laboratory experiments may tend to overestimate heritability within natural populations (e.g. Aspi \& Hoikkala, 1993). However, a recent survey (Weigensberg \& Roff, 1996) revealed surprising concordance between laboratory and field-based determinations of heritability for various characters in a range of species. We have no reason to believe that $A$. grisella signal characters represents an exception.

Previous work on A. grisella showed that the male offspring of attractive sires developed faster, ceteris paribus, than those of nonattractive sires under favourable environmental conditions (Jia \& Greenfield, 1997). Because rapid development may afford selective advantages if food is limiting or the season is short, the relationship between development time and attractiveness suggested that good-genes sexual selection may sometimes operate in A. grisella. Our current data, however, do not support this suggestion. Although development time was significantly heritable for males reared individually (Table 2) and showed significant phenotypic and environmental correlations with various signal characters for males reared collectively, there were no significant genetic correlations between development time and signal characters (Table 3). Thus, there was no indication that females who mate with males that produce attractive signals will necessarily receive genes for rapid offspring development. Clearly, more work on these relationships is needed under an expanded range of environmental conditions.

Directional selection exerted by female choice on male signal characters has traditionally been expected to restrict additive genetic variance for those characters. However, a recent review (Pomiankowski \& Møller, 1995) indicates that additive genetic variance of sexually selected characters is relatively high in many species, and several theoretical treatments (Pomiankowski \& Møller, 1995; Rowe \& Houle, 1996) have been proffered to account for such values.

Our heritability estimates for several signal characters differed markedly between the two rearing conditions. Because the experiments used insects from the stock population at approximately the same time and included relatively large effective population sizes, it is unlikely that genetic differences accounted for differences in the significance of heritability values. If environmental sources of variance are sufficiently high, heritability may be negligible in some environments even though 
additive genetic variance is the same. Thus, additive genetic variance may be overwhelmed by environmental variance under some conditions, and selection by females for preferred male signal characters would be ineffective. Such changes in the strength and direction of selection imposed by females may explain, in part, the maintenance of genetic variance in male signals, and, ultimately, indirect female choice.

Although female choice in $A$. grisella may also result from direct mechanisms such as sensory bias, these mechanisms are not incompatible with indirect arbitrary or good-genes selection (Kirkpatrick, 1996). Moreover, they do not account for the maintenance of genetic variance for signal characters and the persistence of nonattractive males in populations. It is expected that investigations under an extensive range of environmental conditions may ultimately lead to a resolution of this dilemma.

\section{Acknowledgements}

This research was funded by U.S. National Science Foundation grants IBN-9407162 and IBN-9696138 to M.D.G. and R.D.C., and by DFG (Germany) grant no. RE 1167/1-2 to K.R. We are grateful to Ric Roggero of the University of Kansas Instrumentation Design Laboratory and Martin Cremer for developing the signal processing software used in this study, and to W. Andrew Snedden and several anonymous reviewers for critical review of this manuscript.

\section{References}

ANDersson, M. 1994. Sexual Selection. Princeton University Press, Princeton, NJ.

ASPI, J. AND HOIKKALA, A. 1993. Laboratory and natural heritabilities of male courtship song characters in Drosophila montana and Drosophila littoralis. Heredity, 70, 400-406.

BAKKER, T.C. M. AND POMIANKOWSKI, A. 1995. The genetic basis of female mate preferences. J. Evol. Biol., 8, 129-171.

BECKER, W. A. 1975. Manual of Quantitative Genetics, 3rd edn. Academic Enterprises, Pullman, WA.

Charalambous, M., BUTLIN, R. K. AND HewitT, G. M. 1994. Genetic variation in male song and female song preference in the grasshopper Chorthippus brunneus (Orthoptera: Acrididae). Anim. Behav., 47, 399-411.

FALCONER, D. S. 1981. Introduction to Quantitative Genetics, 2nd edn. Longman, Harlow, Essex.

GREENFIELD, M. D. AND COFFELT, J. A. 1983. Reproductive behaviour of the lesser wax moth, Achroia grisella (Pyralidae: Galleriinae): signalling, pair formation, male interactions, and mate guarding. Behaviour, 84, 287-315.

HEDRICK, A. V. 1994. The heritability of mate-attractive traits: a case study on field crickets. In: Boake, C. R. B. (ed.) Quantitative Genetic Studies of Behavioral Evolution, pp. 228-250. University of Chicago Press, Chicago, IL.
HOUdE, A. E. 1997. Sex, Color, and Mate Choice in Guppies, Princeton University Press, Princeton, NJ.

HOULE, D. 1992. Comparing evolvability and variability of quantitative traits. Genetics, 130, 195-200.

JANG, Y. 1997. Evolution and Genetics of Mate Preference in an Ultrasonic Pyralid Moth. PhD Dissertation, University of Kansas, Lawrence.

JANG, Y. AND GREENFIELD, M. D. 1996. Ultrasonic communication and sexual selection in wax moths: female choice based on energy and asynchrony of male signals. Anim. Behav., 51, 1095-1106.

JANG, Y. AND GREENFIELD, M. D. 1998. Absolute versus relative measurements of sexual selection: assessing the contributions of ultrasonic signal characters to mate attraction in lesser wax moths, Achroia grisella (Lepidoptera: Pyralidae). Evolution, 52, 1383-1393.

JANG, Y., COLLINS, R. D. AND GREENFIELD, M. D. 1997. Variation and repeatability of ultrasonic sexual advertisement signals in Achroia grisella (Lepidoptera: Pyralidae). J. Insect Behav., 10, 87-98.

JIA, F.-Y. AND GREENFIELD, M. D. 1997. When are good genes good? Variable outcomes of female choice in wax moths. Proc. R. Soc. B, 264, 1057-1063.

KEARSEY, M. J. AND POONI, H. S. 1996. The Genetical Analysis of Quantitative Traits. Chapman \& Hall, London.

KIRKPATRICK, M. 1996. Good genes and direct selection in the evolution of mating preferences. Evolution, 50, 2125-2140.

LANDE, R. 1981. Models of speciation by sexual selection on polygenic traits. Proc. Natl. Acad. Sci. U.S.A., 78, 3721-3725.

NORUSIS, M. J. 1990. spss/PC + Statistics 4.0. SPSS Inc., Chicago. POMIANKOWSKI, A. 1988. The evolution of female mate preferences for male genetic quality. Oxford Surv. Evol. Biol., 5, 137-183.

POMIANKOWSKI, A. AND MøLlER, A. P. 1995. A resolution of the lek paradox. Proc. R. Soc. B, 260, 21-29.

REINHOLD, K., GREENFIELD, M. D., JANG, Y. AND BROCE, A. 1998. Energetic cost of sexual attractiveness: ultrasonic advertisement in wax moths. Anim. Behav., 55, 905-913.

RITCHIE, M. G. 1996. What is the 'paradox of the lek'? Trends Ecol. Evol., 11, 175.

ROWE, L. AND HOULE, D. 1996. The lek paradox and the capture of genetic variance by condition dependent traits. Proc. $R$. Soc. B, 263, 1415-1421.

SEARLe, S. R. 1971. Linear Models. John Wiley, New York.

SNEDDEN, W. A., TOSH, C. R. AND RITChIE, M. G. 1994. The ultrasonic mating signal of the male lesser wax moth. Physiol. Entomol., 19, 367-372.

SOKAL, R. S. AND ROHLF, R. J. 1981. Biometry: Principles and Practices of Statistics in Biological Research, 2nd. edn. W. H. Freeman, New York.

SPANGLER, H. G., GREENFIELD, M. D. AND TAKESSIAN, A. 1984. Ultrasonic mate calling in the lesser wax moth. Physiol. Entomol., 9, 87-95.

WEBB, K. L. AND ROFF, D. A. 1992. The quantitative genetics of sound production in Gryllus firmus. Anim. Behav., 44, 823-832.

WEIGENSBERG, I. AND ROFF, D. A. 1996. Natural heritabilities: can they be reliably estimated in the laboratory? Evolution, 50, 2149-2157. 